\title{
Gender and age differences in polysomnography findings and sleep complaints of patients referred to a sleep laboratory
}

\author{
A. Silva1, M.L. Andersen¹, M.T. De Mello1, L.R.A. Bittencourt ${ }^{1}$, D. Peruzzo² and \\ S. Tufik ${ }^{1}$ \\ 1Departamento de Psicobiologia, Escola Paulista de Medicina, Universidade Federal de São Paulo, \\ São Paulo, SP, Brasil \\ 2Departamento de Periodontia, Faculdade de Odontologia de Piracicaba, Universidade Estadual de \\ Campinas, Campinas, SP, Brasil
}

Correspondence to: M.L. Andersen, Departamento de Psicobiologia, EPM, UNIFESP, Rua Napoleão de Barros, 925, 04024-002 São Paulo, SP, Brasil

Fax: +55-11-5572-5092. E-mail: mandersen@psicobio.epm.br

\begin{abstract}
Our objective was to examine the effect of gender on the sleep pattern of patients referred to a sleep laboratory. The data (questionnaires and polysomnographic recordings) were collected from a total of 2365 patients (1550 men and 815 women). The polysomnography permits an objective assessment of the sleep pattern. We included only polysomnography exams obtained with no more than one recording system in order to permit normalization of the data. Men had a significantly higher body mass index than women $\left(28.5 \pm 4.8 \mathrm{vs} 27.7 \pm 6.35 \mathrm{~kg} / \mathrm{m}^{2}\right)$ and had a significantly higher score on the Epworth Sleepiness Scale (10.8 \pm 5.3 vs $9.5 \pm 6.0$ ), suggesting daytime sleepiness. Women had a significantly higher sleep latency than men, as well as a higher rapid eye movement (REM) latency. Men spent more time in stages 1 (4.6 \pm 4.1 vs $3.9 \pm 3.8)$ and 2 (57.0 \pm 10.5 vs $55.2 \pm 10.1)$ of non-REM sleep than women, whereas women spent significantly more time in deep sleep stages ( 3 and 4$)$ than men (22.6 \pm 9.0 vs $19.9 \pm 9.0)$. The apnea/hypopnea and arousal indexes were significantly higher and more frequent in men than in women $(31.0 \pm 31.5$ vs $17.3 \pm 19.7)$. Also, periodic leg movement index did not differ significantly between genders, but rather differed among age groups. We did not find significant differences between genders in the percentage of REM sleep and sleep efficiency. The results of the current study suggest that there are specific gender differences in sleep pattern.
\end{abstract}

Key words: Sleep; Gender; Polysomnography; Apnea; Insomnia; Database

Research supported by grants from Associação Fundo de Incentivo à Psicofarmacologia (AFIP), Instituto do Sono/AFIP, and FAPESP (CEPID \#98/14303-3 to S. Tufik and \#07/56620-6, Master's degree, to A. Silva). S. Tufik, L.R.A. Bittencourt, M.T. De Mello and M.L. Andersen are recipients of CNPq fellowships.

Received December 3, 2007. Accepted November 28, 2008

\section{Introduction}

Although sleep is an integral aspect of the function of diurnal organisms and an essential part of health and wellness, the consequences of sleep disturbances have been documented essentially only in men. Indeed, the influence of gender on the severity of sleep disturbances and the distribution of sleep events during the sleep cycle has been reported in only a few studies (1-3). However, in sleep surveys, women report considerably more sleep problems than men (4-6).

A survey comparing the prevalence of complaints of sleep disorders of the adult population in the city of São Paulo (Brazil) carried out in 1987 and 1995 reported that women had a higher prevalence of complaints about the difficulty in initiating sleep in both surveys (7). Furthermore, 
women tend to sleep more than men (8) and longer sleep durations have been reported in adult women based on subjective or objective data (9). Polysomnographically measured sleep quality appears to be poorer in elderly men than in women (10). In view of the prevalence of data collected from men, it is not yet clear which factors contribute the most to the sleep disturbances reported by women (11).

Polysomnography (PSG) permits an objective assessment of the sleep pattern of an individual by recording the multiple physiological events that occur throughout a night's sleep. PSG has become an essential resource in the examination of the nocturnal sleep pattern and is instrumental in the diagnosis of sleep disorders (12). To date, however, gender differences in PSG measures have not been thoroughly examined and conflicting data have been reported in small sample investigations. Thus, the aim of the present study was to examine the influence of gender on sleep patterns obtained by two methods, i.e., PSG and questionnaires, in a retrospective study in a population of 1550 men and 815 women referred to a Sleep Institute associated with a public University Hospital (UNIFESP).

\section{Material and Methods}

After approval by the Ethics Committee of the Universidade Federal de São Paulo (UNIFESP, CEP \#07/0584), the PSG records contained in the database of the Sleep Institute/Associação Fundo de Incentivo à Psicofarmacologia (AFIP) were assessed.

\section{Subjects}

All patients who had complaints related to sleep and who were duly registered in the database of the Sleep Institute/ AFIP (São Paulo, Brazil) participated in the investigation. All patients gave written informed consent that was included in the pre-sleep questionnaire authorizing data to be utilized in future research. A total of 6458 patients were referred to the clinic by physicians for a PSG exam in 2006.

Of these 6458 patients, 2365 patients (1550 men and 815 women) were selected from the database from March to December 2006. We included only PSG exams obtained with no more than one recording system in order to permit normalization of the data; thus, 2365 patients were included in the current study. The database contains a total of 71,205 patients who were registered between 1997 and 2007. After they answered the UNIFESP Sleep Questionnaire (7) and the Epworth Sleepiness Scale (ESS) questionnaires, all patients underwent nocturnal PSG $(13,14)$.

Our Sleep Institute is a national reference center staffed by a multidisciplinary group, and the physicians responsible for assessing the sleep disorders use the same stan- dardized questionnaire to evaluate the patients. The data collected from the charts were classified by age, gender, body mass index (BMI), ESS, and PSG parameters. Inclusion criteria were: basal PSG (patient's first time) for individuals with sleep disorder complaints who came to the Sleep Institute in 2006, had their PSG recorded, and allowed their data to be used in future research. Exclusion criteria were: a second PSG for the same patient (for treatment) or if the patient did not sign the authorization allowing his or her data to be used in future investigations. To standardize the data, we included only patients recorded in a single type of acquisition system.

\section{Procedures}

On the evening of the PSG recording, all patients filled out the pre-sleep questionnaire and authorized or not their data to be used in future research. The patient was subsequently led to the room where the PSG recording was conducted. Once the equipment was set up and wired, PSG recordings were initiated, with the regular sleeping hours of each patient being observed whenever possible. On the following day, the patient filled out a post-sleep questionnaire and was released.

\section{Data collection instruments}

Data were collected by means of questionnaires and objectively by PSG. The information was gathered and organized in the database of the Sleep Institute/AFIP. The data from both questionnaires and PSG were typed and double-checked.

\section{The Epworth Sleepiness Scale}

The ESS questionnaire is composed of 8 self-answer questions involving passive or active day-to-day situations, with the patient being asked to answer on a scale of 0 (no chance) to 3 (high chance) what chance he would have to nap in each of the situations (13). Scores of more than 10 suggest significant daytime sleepiness, and scores of 15 and over indicate the existence of pathological sleepiness in specific conditions, such as apnea and narcolepsy.

\section{Sleep questionnaires}

The UNIFESP Sleep Questionnaire was elaborated by the team of the Sleep Institute/AFIP (7). The pre-sleep questionnaire contains aspects of the day and evening prior to the PSG. This questionnaire may indicate possible alterations in the result of the recording, such as the presence of certain medications or the consumption of alcohol within 24 $\mathrm{h}$ before the recording. The post-sleep questionnaire was applied on the morning subsequent to the recording night and served to collect information about the patient's night to 
aid the analysis of the PSG, providing subjective information that was compared to objective findings (PSG parameters).

\section{Polysomnography}

Overnight PSG recordings were performed using an EMBLA digital system (17 channels, Flaga hf. Medical Devices, Iceland). The following variables were monitored: electroencephalogram (four channels: C3-A2, C4A1, O1-A2, O2-A1), electrooculogram (two channels: LOCA2, ROC-A1), and electromyogram (two channels: submental and anterior tibialis muscles) using surface electrodes, and electrocardiogram (one channel), snoring, and body position detected with EMBLA sensors. Airflow was detected by a thermocouple and by a pressure flow transducer. Chest and abdominal piezoelectric sensors monitored respiratory effort. Arterial oxygen saturation and pulse were recorded using a pulse oximeter.

All PSG exams were performed and scored based on the guidelines for sleep studies (15). Arousals and leg movements were defined according to the report from the Sleep Disorders Atlas Task Force of the American Sleep Disorders Association (ASDA) (16). Respiratory events were defined according to the report of an American Academy of Sleep Medicine Task Force (AASM) (16).

\section{Statistical analysis}

Sleep data are reported as means \pm SEM. Gender data were analyzed by the Student $t$-test. Two-way ANOVA tests were conducted to determine differences associated with age and gender and the interaction between these two factors. The Tukey post hoc test was used to compare values obtained at different times between groups. The level of significance was set at $\mathrm{P}<0.05$.

\section{Results}

\section{Sleep complaints reported by the individuals}

All patients who participated in this investigation sought our Institute because of some sleep complaint, with snoring being the main complaint for both genders. Women complained more frequently of somnolence when answering the pre-sleep questionnaire (9.69 vs $4.45 \%$, Table 1), a fact that was not confirmed by the results collected from the ESS questionnaire (Figure 1). ANOVA followed by the Tukey test $\left(F_{(1,2317)}=25.42 ; \mathrm{P}<0.0001\right)$ revealed that men had $a$ significantly higher ESS score than women (10.8 \pm 5.3 vs 9.5 \pm 6.0 ), which is suggestive of daytime sleepiness. The analysis of different ages revealed that men were sleepier than women $\left(F_{(1,2306)}=14.30 ; P<0.0001\right)$, and statistical differences were found for age effect $\left(F_{(5,2306)}=4.09\right.$; $P<$ 0.001 ), as shown in Figure 1. Men in their forties had higher
ESS values when compared with the youngest group $(\mathrm{P}<$ 0.04). For both genders, the 61-70-year group differed from the 31-40-year $(P<0.02)$ and 41-50-year $(P<0.04)$ groups. Statistically significant differences were observed at 31-40 $(P<0.01), 41-50(P<0.05)$, and $51-60$ years $(P<0.04)$ compared to individuals over 70 years old. Analysis of the data obtained with the PSG exams revealed that apnea was

Table 1. Prevalence of sleep complaints reported by the patients when responding to the pre-sleep questionnaire.

\begin{tabular}{lcc}
\hline & $\begin{array}{c}\text { Women } \\
(\mathrm{N}=815)\end{array}$ & $\begin{array}{c}\text { Men } \\
(\mathrm{N}=1550)\end{array}$ \\
\hline Apnea & $3.4 \%(28)$ & $3.67 \%(57)$ \\
Tiredness & $0.36 \%(3)$ & $0.25 \%(4)$ \\
Body pain & $0.72 \%(6)$ & $0.06 \%(1)$ \\
Insomnia & $13.37 \%(109)$ & $3.09 \%(48)$ \\
Sleep interruptions & $1.96 \%(16)$ & $0.96 \%(15)$ \\
Limb movement & $1.22 \%(10)$ & $0.83 \%(13)$ \\
Bruxism & $0.24 \%(2)$ & $0.06 \%(1)$ \\
Snoring & $62.57 \%(510)$ & $81.03 \%(1256)$ \\
Sleep-walking & $0.36 \%(3)$ & $0.06 \%(1)$ \\
Agitated sleep & $0.49 \%(4)$ & $0.45 \%(7)$ \\
Light sleep & $1.84 \%(15)$ & $0.83 \%(13)$ \\
Excessive daytime sleepiness & $9.69 \%(79)$ & $4.45 \%(69)$ \\
Other reasons & $3.68 \%(30)$ & $4.19 \%(65)$ \\
\end{tabular}

Data are reported as percent of group with number of persons within parentheses.

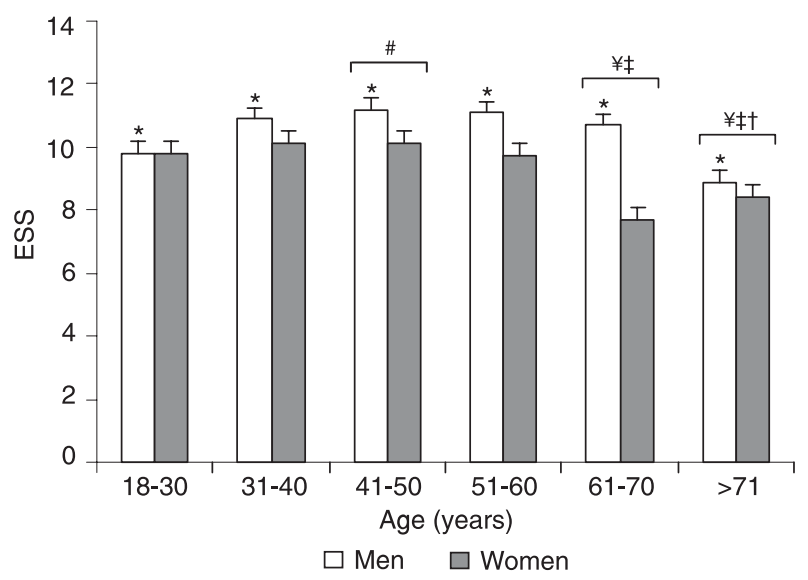

Figure 1. Epworth Sleepiness Scale (ESS) score as a function of gender and age. Data are reported as means \pm SEM for a total of 1550 males and 815 females. Age ranges: $18-30$ years $(N=243$ males, 100 females); $31-40$ years $(\mathrm{N}=392$ males, 148 females); 41-50 years $(\mathrm{N}=432$ males, 192 females); $51-60$ years $(\mathrm{N}=324$ males, 222 females); $61-70$ years $(\mathrm{N}=118$ males, 104 females); $>70$ years $(\mathrm{N}=41$ males, 40 females $) .{ }^{*} \mathrm{P}<0.05$ comparing genders; $\# \mathrm{P}<0.05$ compared to subjects aged $18-30$ years; ${ }^{\sharp} \mathrm{P}<$ 0.05 compared to subjects aged $31-40$ years; $¥ \mathrm{P}<0.05$ compared to subjects aged 41-50 years; $\mathrm{T}_{\mathrm{P}}<0.05$ compared to subjects aged 51-60 years (ANOVA followed by the Tukey test). 
the main sleep disturbance in both genders (Table 2), in agreement with the initial complaint of snoring.

\section{Comparison of sleep pattern between genders}

The average age of men in the study was $44.0 \pm 12.7$ years, and that of women was $47.9 \pm 13.8$ years. Men had a significantly higher BMI than women $(28.5 \pm 4.8$ vs 27.7 $\left.\pm 6.35 \mathrm{~kg} / \mathrm{m}^{2} ; \mathrm{P}<0.001\right)$. The PSG data are presented in Table 3. Women had significantly higher sleep latency $(\mathrm{P}<$ $0.0001)$ and rapid eye movement (REM) latency $(P<$ 0.001 ) than men.

Statistical analysis of the sleep stages revealed that men spent more time in stage $1(\mathrm{P}<0.001)$ and stage $2(\mathrm{P}$ $<0.0001$ ) of non-REM (NREM) sleep than women. In contrast, women spent significantly more time $(P<0.0001)$ in the deeper stages of sleep ( 3 and 4$)$ than men.

Regarding sleep disturbances, the apnea/hypopnea

Table 2. Prevalence of sleep disturbances of men and women detected by polysomnography recording.

\begin{tabular}{lcc}
\hline & $\begin{array}{c}\text { Women } \\
(\mathrm{N}=815)\end{array}$ & $\begin{array}{c}\text { Men } \\
(\mathrm{N}=1550)\end{array}$ \\
\hline $\mathrm{PLMI}>5$ to $\leq 25$ events/h & $13.61 \%(111)$ & $8.38 \%(130)$ \\
$\mathrm{PLMI}>25$ to $\leq 50$ events/h & $2.33 \%(19)$ & $2.77 \%(43)$ \\
$\mathrm{PLMI}>50$ events/h & $0.98 \%(8)$ & $0.70 \%(11)$ \\
$\mathrm{AHI}>5$ to $\leq 15$ events/h & $27.36 \%(223)$ & $31.80 \%(493)$ \\
$\mathrm{AHI}>15$ to $\leq 30$ events/h & $18.65 \%(152)$ & $24.64 \%(382)$ \\
$\mathrm{AHI}>30$ events/h & $19.38 \%(158)$ & $37.03 \%(574)$
\end{tabular}

Data are reported as percent of group with number of persons within parentheses. $\mathrm{PLMI}=$ periodic leg movement index; $\mathrm{AHI}=$ apnea-hypopnea index.

Table 3. Comparison of sleep parameters obtained by polysomnography between genders.

\begin{tabular}{lcc}
\hline & $\begin{array}{c}\text { Women } \\
(\mathrm{N}=815)\end{array}$ & $\begin{array}{c}\text { Men } \\
(\mathrm{N}=1550)\end{array}$ \\
\hline Sleep latency (min) & $25.9 \pm 29.1$ & $20.5 \pm 23.5^{*}$ \\
REM latency (min) & $129.7 \pm 72.7$ & $119.4 \pm 68.5^{*}$ \\
Sleep efficiency (\%) & $81.6 \pm 12.4$ & $82.4 \pm 11.9$ \\
Stage 1 (\%) & $3.9 \pm 3.8$ & $4.6 \pm 4.1^{*}$ \\
Stage 2 (\%) & $55.2 \pm 10.1$ & $57.0 \pm 10.5^{*}$ \\
Stages 3 and 4 (\%) & $22.6 \pm 9.0$ & $19.9 \pm 9.0^{*}$ \\
Stage REM (\%) & $18.0 \pm 6.7$ & $18.4 \pm 6.6$ \\
Microarousal index & $15.2 \pm 9.9$ & $18.6 \pm 13.1^{*}$ \\
AHI (events/h) & $17.3 \pm 19.7$ & $31.0 \pm 31.5^{*}$ \\
PLMI (events/h) & $3.6 \pm 11.1$ & $2.8 \pm 9.0$ \\
\hline
\end{tabular}

Data are reported as means \pm SEM. REM = rapid eye movement; $\mathrm{AHI}=$ apnea-hypopnea index; PLMI = periodic leg movement index. ${ }^{*} \mathrm{P}<0.05$ compared to women (ANOVA followed by the Tukey test). index (AHI; $\mathrm{P}<0.0001)$ and the microarousal index $(\mathrm{P}<$ 0.0001 ) were significantly higher and more frequent in men than in women. However, we observed no significant differences between genders in the percentage of REM sleep, sleep efficiency, and periodic leg movement index (PLMI; P > 0.05).

\section{Comparison of polysomnographic sleep between genders at different ages}

Figures 2 to 5 describe the nocturnal PSG sleep measures for men and women at different ages. Sleep onset latency, i.e., the time it takes to initially fall asleep (Figure $2)$, was significantly different between genders $\left(F_{(1,2351)}=\right.$ 19.33; $P<0.0001)$ and across different ages $\left(F_{(5,2351)}=\right.$ 5.94; $\mathrm{P}<0.0001)$. Moreover, REM sleep latency (Figure 2) differed between genders $\left(F_{(1,2331)}=7.35 ; P<0.01\right)$ and age ranges $\left(F_{(5,2331)}=2.59 ; P<0.02\right)$, and the latency was higher at 70 years compared to $31-40(P<0.04)$ and $41-50$ years $(P<0.01)$.
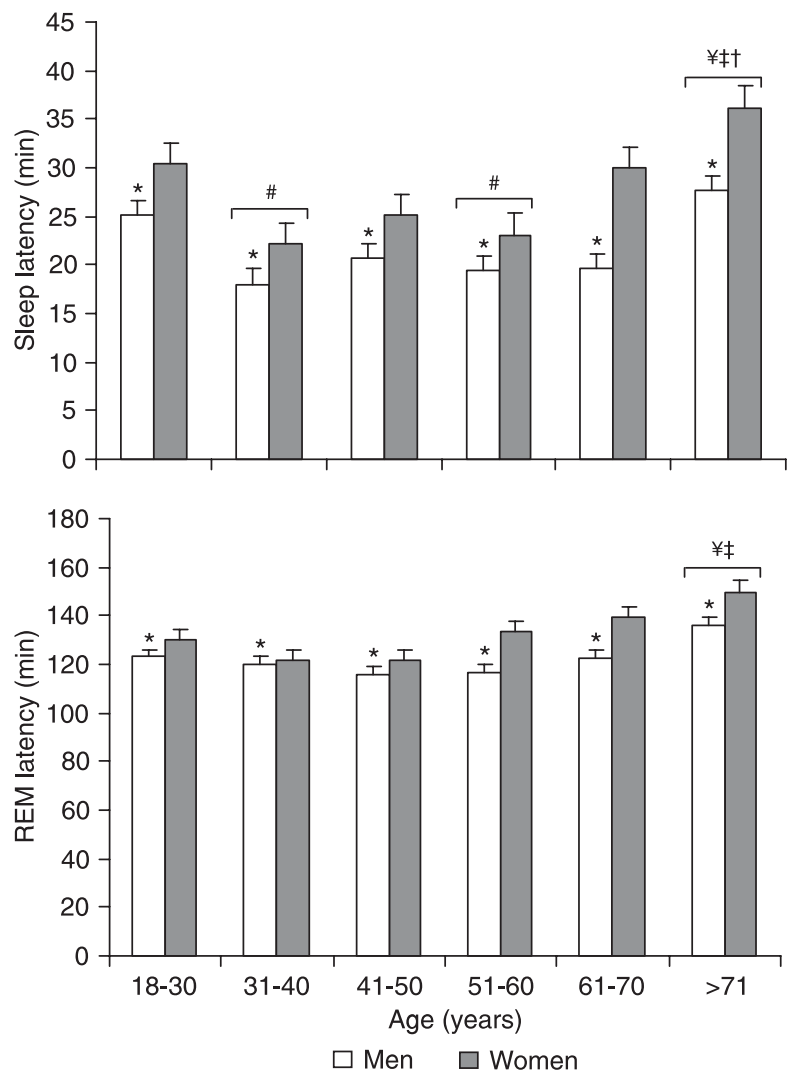

Figure 2. Sleep latency and rapid eye movement (REM) latency as a function of gender and age. Data are reported as means \pm SEM polysomnographic recordings for a total of 1550 males and 815 females. See Figure 1 legend for age range and gender. Data are from overnight latency. ${ }^{*} P<0.05$ between genders; ${ }^{¥} P<0.05$ compared to subjects aged $31-40$ years; $¥ \mathrm{P}<0.05$ compared to subjects aged $41-50$ years (ANOVA followed by the Tukey test). 
Stage 1 differed between genders $\left(F_{(1,2351)}=16.18 ; P<\right.$ $0.0001)$ and ages $\left(F_{(5,2351)}=5.43 ; P<0.0001\right)$, as illustrated in Figure 3. Comparison of mean ages showed that stage 1 was significantly higher in the elderly group than in the 18-30-year $(P<0.0001)$ and 31-40-year $(P<0.01)$ groups. Stage 2 was significantly higher at $41-50$ years $(P$ $<0.03)$ and over 71 years $(P<0.04)$ compared to the third decade of life $\left(F_{(5,2352)}=3.40 ; P<0.01\right)$, and differed between genders $\left(F_{(1,2352)}=17.41 ; P<0.0001\right.$; Figure 3$)$.
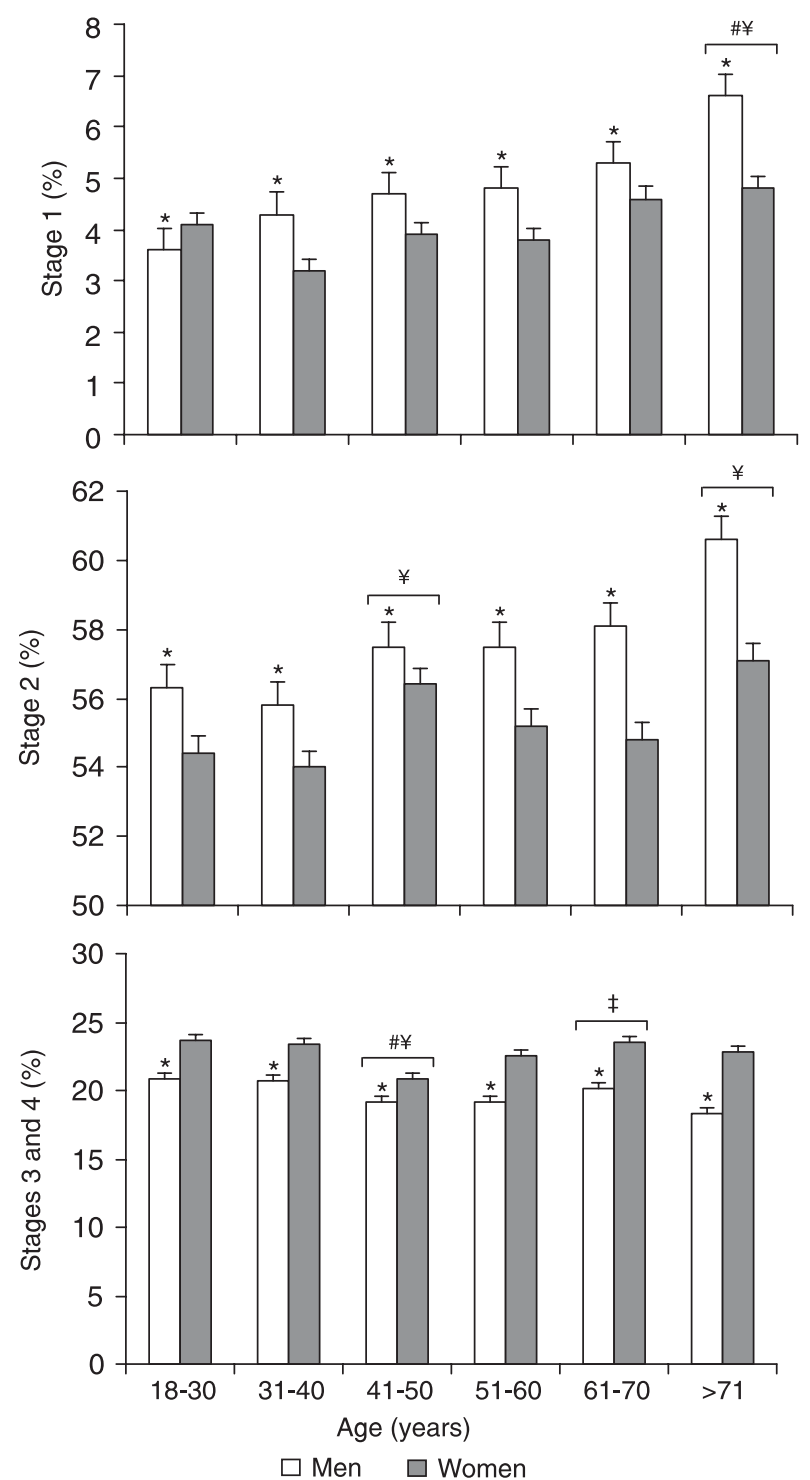

Figure 3. Stages 1, 2, 3, and 4 sleep as a function of gender and age. Data are reported as means \pm SEM for a total of 1550 males and 815 females. See Figure 1 legend for age range and gender. ${ }^{*} P$ $<0.05$ between genders; ${ }^{P} P<0.05$ compared to subjects aged 1830 years; $¥ \mathrm{P}<0.05$ compared to subjects aged $31-40$ years; $¥ \mathrm{P}<$ 0.05 compared to subjects aged $41-50$ years (ANOVA followed by the Tukey test).
Analysis of stages 3 and 4 showed gender $\left(\mathrm{F}_{(1,2352)}=\right.$ 41.64; $\mathrm{P}<0.0001)$ and age effects $\left(\mathrm{F}_{(5,2352)}=3.82 ; \mathrm{P}<\right.$ 0.01 ). There was a clear reduction due to age at $41-50$ years compared to $18-30$ and $31-40$ years (Ps $<0.01$ ). Furthermore, there were differences between $61-70$ and 41-50 years $(P<0.04$; Figure 3$)$.

Sleep efficiency was similar for males and females, but an age effect was found $\left(F_{(5,2352)}=37.89 ; P<0.0001\right)$. As shown in Figure 4, the 41-50-year groups had less sleep time than the respective preceding younger groups (Ps < $0.01)$. Subjects over 70 years differed from those aged 18 30 and $61-70$ years $(P<0.01)$.

The present data showed an age effect $\left(F_{(5,2352)}=\right.$ 10.60; $P<0.0001$ ), but not a gender effect, for REM sleep, seen as a small but clear reduction in REM at age 61-70 (Ps $<0.01$ ) and over 70 years (Ps $<0.0001)$ compared to previous ages (Figure 4).
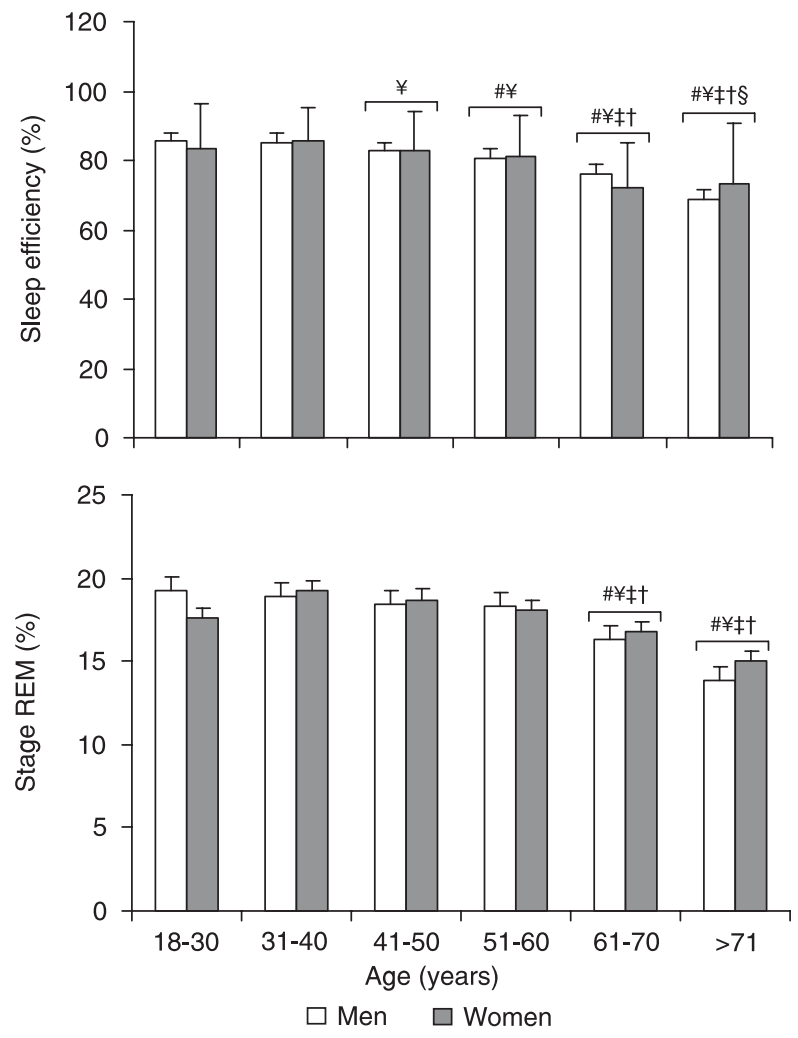

Figure 4. Sleep efficiency and percent rapid eye movement (REM) sleep as a function of gender and age. Data are reported as means \pm SEM for a total of 1550 males and 815 females. See Figure 1 legend for age range and gender. ${ }^{P} P<0.05$ compared to subjects aged 1830 years; $¥ \mathrm{P}<0.05$ compared to subjects aged $31-40$ years; $¥ \mathrm{P}<$ 0.05 compared to subjects aged $41-50$ years; ${ }^{\dagger} \mathrm{P}<0.05$ compared to subjects aged $51-60$ years; $\$ \mathrm{P}<0.05$ compared to subjects aged 61 70 years (ANOVA followed by the Tukey test). 
All statistically significant data concerning sleep events are shown in Figure 5. Analysis of the arousal index revealed a gender $\left(F_{(1,2348)}=71.30 ; P<0.0001\right)$ and age effect $\left(F_{(5,2348)}=15.10 ; P<0.0001\right)$. The groups over 40 years of age differed from the group aged 18-30 (Ps <
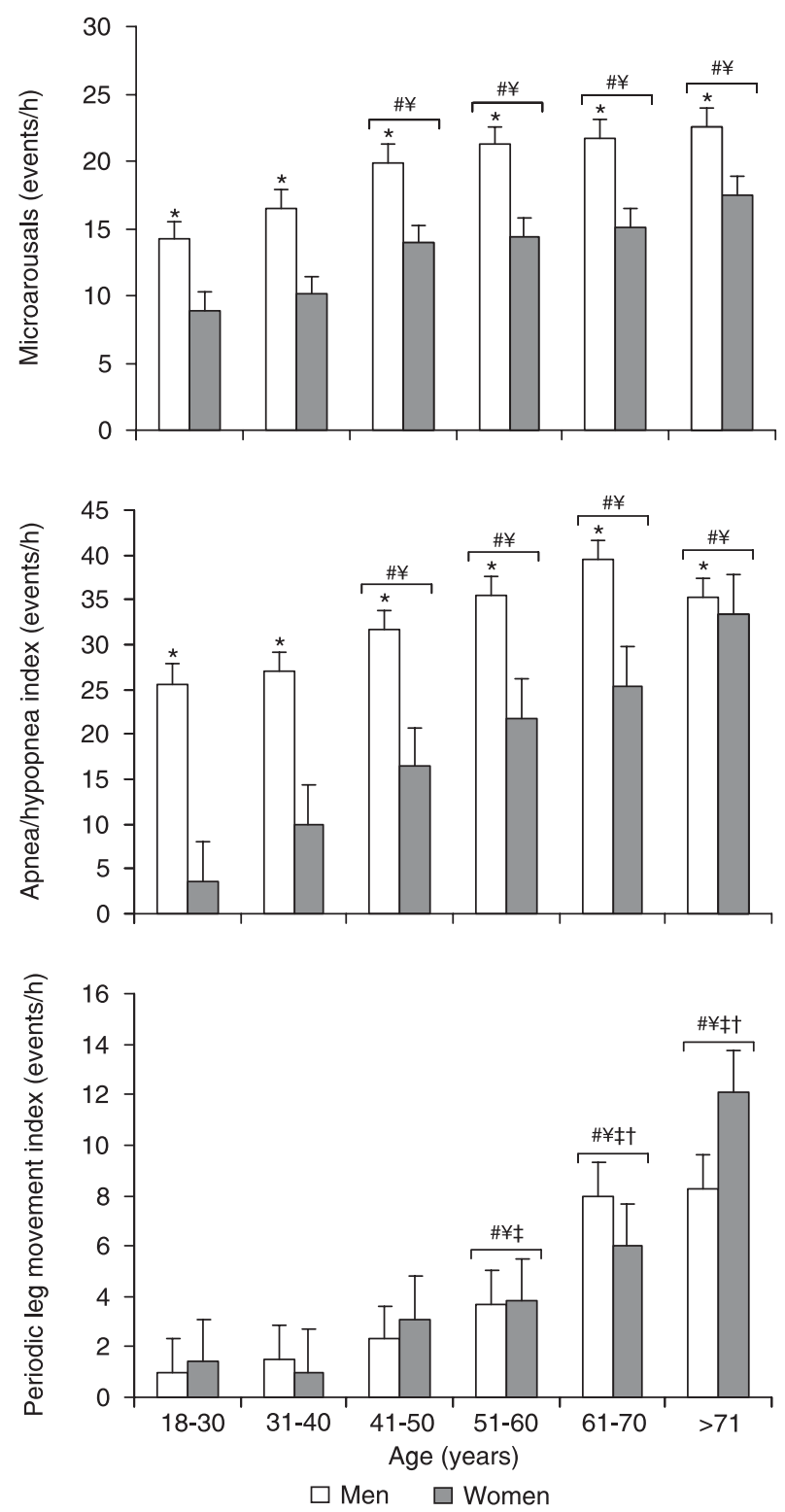

Figure 5. Sleep disturbances as a function of gender and age. Data are reported as means \pm SEM for a total of 1550 males and 815 females. See Figure 1 legend for age range and gender. ${ }^{*} P$ $<0.05$ between genders; $\mathrm{P}<0.05$ compared to subjects aged $18-30$ years; $¥ \mathrm{P}<0.05$ compared to subjects aged $31-40$ years. $\ddagger \mathrm{P}<0.05$ compared to subjects aged $41-50$ years; $\mathrm{\dagger P}<0.05$ compared to subjects aged 51-60 years (ANOVA followed by the Tukey test).
$0.0001)$ and $31-40$ years $(P s<0.01)$. As expected, the mean respiratory disturbance index differed significantly between genders $\left(F_{(1,2352)}=92.72 ; P<0.0001\right)$ and ages $\left(F_{(5,2352)}=20.00 ; P<0.0001\right)$. At all ages, AHI was greater in men than in women. From 41-50 years, all groups had a higher index than the groups aged 18-30 years (Ps < 0.001 ) and $31-40$ years (Ps < 0.04). PLMI differed markedly across ages, as evidenced by a significant age effect $\left(F_{(5,2216)}=22.39 ; P<0.0001\right)$, but not between genders, as determined ANOVA and the Tukey test. PLMI increased with age, differing significantly from younger groups starting with the group in its fifties ( $P s<0.01)$.

\section{Discussion}

In the present study, we examined the sleep patterns of individuals with sleep complaints and observed that men feel sleepier than women. However, PSG data did not reveal significant differences in sleep efficiency between genders. Men generated longer periods of stage 1 and 2 NREM, whereas women took a significantly longer time to fall into NREM sleep and spent more time in stages 3 and 4. These contrasting results may be due to the fact that the male subjects who answered the questionnaire had more numerous apneic events and microarousals than women. Also, PLMI did not differ significantly between genders, but rather differed among age groups.

With respect to sleep pattern, little attention has been given to whether sleep is differentially regulated between genders. Of note, the sleep patterns found in the present study for the two genders originated from individuals in our database with sleep complaints and, thus, cannot be extrapolated to the general population with no sleep complaints.

Recently, a study used a meta-analysis approach to investigate sex differences in the risk of insomnia and indicated the clear need to develop a better understanding of how gender influences sleep (17). Sleep disturbances, such as insomnia, are a frequent complaint among women who report more sleep difficulties than men $(5,18)$. Indeed, nightmares were twice as prevalent in women as in men (19). The reasons for such discrepancies are attributed to hormonal fluctuations over the menstrual or estrous cycles, a factor that has been associated with sleep variations in both humans and rats (20-22).

The loss of sleep that results from our modern lifestyle, increased work pressure, and psychosocial stress may have many unknown repercussions on health and wellness $(23,24)$, and the problem might be further aggravated for women due to additional child care and home tasks. The well-documented constellation of consequences of sleep 
restriction established for males remains to be demonstrated in females. In fact, it is widely accepted that excessive daytime somnolence is markedly present in the male gender. Few studies, however, have reported the gender difference in excessive daytime somnolence (19).

Many factors can be attributed to the putative cause of this excessive somnolence, such as type of labor, shiftwork, sleep-wake schedules, and sleep-breathing disorders, among others. In the present study, we examined the gender differences in a sample that had sought medical assistance due to sleep complaints. Of note, analysis of the database revealed that more men sought a medical diagnosis (1550) than women (815), and the main complaint was snoring. Among the 1550 men evaluated, the ESS score was $10.8 \pm 5.3$, a figure that is suggestive of somnolence. Still, $8.7 \%$ of that sample presented serious sleepiness (a score over 20). Of note, daytime somnolence scores decreased with age in both genders and differed between men and women, as described by Tsuno and colleagues (25) who investigated somnolence in the apneic elderly. The decrease of ESS may be attributable to physiological factors associated with aging, but these factors are yet to be identified, requiring additional studies to understand the neurobiological events that are orchestrated during sleep throughout the older lifespan.

To our knowledge, the present study was the first to measure gender differences in PSG and questionnaire data in a large group of patients. The 2365 patients studied underwent a standardized and full-criteria PSG/ESS, allowing a reliable evaluation of the effects of specific gender on sleep pattern. One limitation of the present study was the single night of PSG. One may speculate that differences in adaptation to the laboratory could potentially influence the response to sleep. According to Armitage and colleagues (26), little evidence of gender differences in sleep architecture can be collected from one sleep night. Due to the large sample of subjects recorded, however, we do not believe that the significances found in the present study could be attributed to an adaptation issue.

Gender differences in PSG findings have been minimally reported, although PSG provides an ideal means for assessing specific sex differences in sleep regulation. In this context, women had more deep sleep (stages 3 and 4) than men, which agrees with previous laboratory-based normative sleep values (27). Studies have documented that, while healthy women appear to objectively have a better sleep quality than men, women of all adult age groups report more sleep problems, including inadequate sleep time and insomnia $(17,18,28)$. It has been noted that women generally report symptoms more often than men, perhaps due to less restrictive social sanctions for women
(29). Indeed, insomnia and increased sleep latency are frequent complaints in the female gender $(18,29)$. As illustrated in Figure 2, this was a constant finding in all ages evaluated.

The sleep literature has traditionally been biased towards young adult subjects, so that other age groups have not been equally represented. There is currently only limited information about the healthy, middle-aged population (27). The present investigation revealed significant differences in sleep variables between genders and between age groups. Males, particularly in the middle-aged and eldest groups, had more light sleep than females, whereas females had more deep sleep than males. For sleep latency, we found a clear relationship between nocturnal sleep latency and either age or gender, but the middleaged female group fell asleep faster than the eldest group. Similar to earlier reports (30), the clearest age-related changes were in slow wave sleep and REM, which declined substantially with age.

An increased time for women to initiate sleep has been previously reported (18) and was also demonstrated in our PSG study, suggesting that insomnia is a more prevalent disorder in women and that it may be one of the causes of their more frequent complaints about their sleep quality. As also observed in a study by Vagiakis et al. (31), REM sleep latency was also longer in women than in men. Taken altogether, differences between genders could be due to the effects of cyclic levels of female reproductive hormones on sleep $(20,32)$. Conceivably, this suggests that women are either more susceptible to clinical symptoms deriving from inadequate sleep or are more likely to report symptoms in general (33). For instance, in many cases women play the dual role of mother/housewife and professional, working during periods when they should be resting. This causes these women to be in a constant state of sleep restriction.

Several studies have reported that sleep, sleep disorders, and sleep-disordered breathing differ in important ways between men and women and that such respiratory disorders become aggravated with age. In clinical populations, the presentation of obstructive sleep apnea in women is distinct from that of men and is less likely to include a classic history of witnessed apnea or heavy snoring (34). These findings support the influence of sex hormones on gender differences in sleep-disordered breathing. Conceivably, these facts are consistent with the hypothesis that hormones such as progesterone must be involved in sleep regulation and might play a functional role in the regulation of different behavior in women compared to men (35). Netzer and colleagues (36) have demonstrated that reductions in female sex hormones are associated 
with an increased probability of sleep-disordered breathing in women with daytime sleepiness.

Sleep apnea has a significant gender effect on the prevalence of sleep-disordered breathing with a male to female ratio of approximately 10:1 among patients seen in sleep disorder clinics (37) and of approximately 2:1 in an epidemiological sample of mid-life adults (38). Because sleep apnea increases in postmenopausal women, it has been suggested that gonadal hormones, particularly progesterone, might protect women from sleep-disordered breathing during their reproductive years (35). Recently, a cohort study of 1010 Greek patients diagnosed with obstructive sleep apnea demonstrated that this disorder was five times more common in men and that apneic events were also more frequent in men than in women (31).

Sleep disturbances have become a major concern for public health officials and physicians alike as their occurrence has soared in the past decades. It has been observed that most of the people who report sleep complaints feel excessive daytime sleepiness, irritability, and stress (39). The male population is more exposed to such perils, and, indeed, the sleep disturbance that causes most daytime sleepiness is obstructive sleep apnea (40).

As pointed out by Krishnan and Collop (33), gender differences in sleep quality and sleep efficiency have been established in healthy individuals. These differences are magnified in the presence of sleep disorders, such as insomnia and obstructive sleep apnea, which further dis- rupt nocturnal sleep and subsequent daytime functioning. While there are recognized gender differences in the hormone milieu, body fat composition, physical attributes, and even different gender reactions to sleep disorders, it would clearly be an oversimplification to conclude that these are the only differences between men and women.

The results of the current study suggest that there are specific gender differences in sleep pattern, with more sleepiness (ESS) and prevalence of higher sleep disturbance indicators (apneic events) in men. In turn, women take longer to initiate sleep, although their sleep is better preserved due to increased stages 3 and 4 of NREM, and they experience significantly less arousals and apneic events. This study, besides offering insight into women's health issues related to sleep architecture, provides complementary data about controversial issues and emphasizes the relevance of understanding gender sleep differences. This comprehension may prove helpful in research as we better understand how gender may be implicated in the risk of developing sleep disorders.

\section{Acknowledgments}

The authors would like to express their cordial thanks to Daniela Gonçalves Lenci of Departamento de Psicobiologia, Universidade Federal de São Paulo, for assistance with the statistics, and Adriana Marinho (AFIP) for assistance in the database.

\section{References}

1. Wahner-Roedler DL, Olson EJ, Narayanan $S$, Sood R, Hanson AC, Loehrer LL, et al. Gender-specific differences in a patient population with obstructive sleep apneahypopnea syndrome. Gend Med 2007; 4: 329-338.

2. Stang A, Moebus S, Mohlenkamp S, Erbel R, Jockel KH. Gender-specific associations of short sleep duration with prevalent hypertension. Hypertension 2008; 51: e15-e16.

3. Alotair H, Bahammam A. Gender differences in Saudi patients with obstructive sleep apnea. Sleep Breath 2008; 12: 323-329.

4. Hublin C, Kaprio J, Partinen M, Heikkila K, Koskenvuo M. Daytime sleepiness in an adult, Finnish population. J Intern Med 1996; 239: 417-423.

5. Lindberg E, Janson C, Gislason T, Bjornsson E, Hetta J, Boman G. Sleep disturbances in a young adult population: can gender differences be explained by differences in psychological status? Sleep 1997; 20: 381-387.

6. Akerstedt $\mathrm{T}$, Knutsson $\mathrm{A}$, Westerholm $\mathrm{P}$, Theorell $\mathrm{T}$, Alfredsson L, Kecklund G. Sleep disturbances, work stress and work hours: a cross-sectional study. J Psychosom Res 2002; 53: 741-748.
7. Pires ML, Benedito-Silva AA, Mello MT, Pompeia SG, Tufik S. Sleep habits and complaints of adults in the city of São Paulo, Brazil, in 1987 and 1995. Braz J Med Biol Res 2007; 40: 1505-1515.

8. Broman JE, Lundh LG, Hetta J. Insufficient sleep in the general population. Neurophysiol Clin 1996; 26: 30-39.

9. Jean-Louis G, Kripke DF, Ancoli-Israel S, Klauber MR, Sepulveda RS. Sleep duration, illumination, and activity patterns in a population sample: effects of gender and ethnicity. Biol Psychiatry 2000; 47: 921-927.

10. Buysse DJ, Reynolds CF III, Monk TH, Hoch CC, Yeager AL, Kupfer DJ. Quantification of subjective sleep quality in healthy elderly men and women using the Pittsburgh Sleep Quality Index (PSQI). Sleep 1991; 14: 331-338.

11. Dzaja A, Arber S, Hislop J, Kerkhofs M, Kopp C, Pollmacher $\mathrm{T}$, et al. Women's sleep in health and disease. J Psychiatr Res 2005; 39: 55-76.

12. Bittencourt LRA, Silva R, Santos RF, Pires MLN, Mello MT. Sonolência excessiva. Rev Bras Psiquiatr 2005; 27: 16-21.

13. Johns MW. A new method for measuring daytime sleepiness: the Epworth sleepiness scale. Sleep 1991; 14: 540-545. 
14. Noda A, Yagi T, Yokota M, Kayukawa Y, Ohta T, Okada T. Daytime sleepiness and automobile accidents in patients with obstructive sleep apnea syndrome. Psychiatry Clin Neurosci 1998; 52: 221-222.

15. Rechtschaffen A, Kales A. A manual of standardized terminology, techniques and scoring system for sleep sages of human subjects. Washington: U.S. Government Printing Office; 1968.

16. Anonymous. Sleep-related breathing disorders in adults: recommendations for syndrome definition and measurement techniques in clinical research. The Report of an American Academy of Sleep Medicine Task Force. Sleep 1999; 22: 667-689.

17. Zhang B, Wing YK. Sex differences in insomnia: a metaanalysis. Sleep 2006; 29: 85-93.

18. Collop NA, Adkins D, Phillips BA. Gender differences in sleep and sleep-disordered breathing. Clin Chest Med 2004; 25: 257-268

19. Ohayon MM, Caulet M, Philip P, Guilleminault C, Priest RG. How sleep and mental disorders are related to complaints of daytime sleepiness. Arch Intern Med 1997; 157: 2645-2652.

20. Hachul de Campos H, Brandão LC, D'Almeida V, Grego $\mathrm{BH}$, Bittencourt LR, Tufik S, et al. Sleep disturbances, oxidative stress and cardiovascular risk parameters in postmenopausal women complaining of insomnia. Climacteric 2006; 9: 312-319.

21. Antunes IB, Andersen ML, Baracat EC, Tufik S. The effects of paradoxical sleep deprivation on estrous cycles of the female rats. Horm Behav 2006; 49: 433-440.

22. Antunes IB, Andersen ML, Alvarenga TA, Tufik S. Effects of paradoxical sleep deprivation on blood parameters associated with cardiovascular risk in intact and ovariectomized rats compared with male rats. Behav Brain Res 2007; 176: 187-192.

23. Meerlo $P$, Koehl M, van der Borght $K$, Turek FW. Sleep restriction alters the hypothalamic-pituitary-adrenal response to stress. J Neuroendocrinol 2002; 14: 397-402.

24. Leibowitz SM, Lopes MC, Andersen ML, Kushida CA. Sleep deprivation and sleepiness caused by sleep loss. Sleep Med Clin 2006; 1: 31-45.

25. Tsuno N, Jaussent I, Dauvilliers $Y$, Touchon J, Ritchie K, Besset A. Determinants of excessive daytime sleepiness in a French community-dwelling elderly population. J Sleep
Res 2007; 16: 364-371

26. Armitage R, Hoffmann RF. Sleep EEG, depression and gender. Sleep Med Rev 2001; 5: 237-246.

27. Hume $\mathrm{KI}$, Van F, Watson A. A field study of age and gender differences in habitual adult sleep. J Sleep Res 1998; 7: 8594.

28. Bixler EO, Vgontzas AN, Lin HM, Vela-Bueno A, Kales A. Insomnia in central Pennsylvania. J Psychosom Res 2002; 53: 589-592.

29. Shaver JL. Women and sleep. Nurs Clin North Am 2002; 37 : 707-718.

30. Bliwise DL. Sleep apnea and cognitive function: where do we stand now? Sleep 1993; 16: S72-S73.

31. Vagiakis E, Kapsimalis F, Lagogianni I, Perraki H, Minaritzoglou A, Alexandropoulou K, et al. Gender differences on polysomnographic findings in Greek subjects with obstructive sleep apnea syndrome. Sleep Med 2006; 7: 424-430.

32. Goel N, Kim H, Lao RP. Gender differences in polysomnographic sleep in young healthy sleepers. Chronobiol Int 2005; 22: 905-915.

33. Krishnan V, Collop NA. Gender differences in sleep disorders. Curr Opin Pulm Med 2006; 12: 383-389.

34. Ambrogetti A, Olson LG, Saunders NA. Differences in the symptoms of men and women with obstructive sleep apnoea. Aust N Z J Med 1991; 21: 863-866.

35. Andersen ML, Bittencourt LR, Antunes IB, Tufik S. Effects of progesterone on sleep: a possible pharmacological treatment for sleep-breathing disorders? Curr Med Chem 2006; 13: 3575-3582.

36. Netzer NC, Eliasson AH, Strohl KP. Women with sleep apnea have lower levels of sex hormones. Sleep Breath 2003; 7: 25-29.

37. Guilleminault C, Quera-Salva MA, Partinen M, Jamieson A. Women and the obstructive sleep apnea syndrome. Chest 1988; 93: 104-109.

38. Manber R, Armitage R. Sex, steroids, and sleep: a review. Sleep 1999; 22: 540-555.

39. Hauri PJ. A cluster analysis of insomnia. Sleep 1983; 6: 326-338.

40. Santos EH, de Mello MT, Pradella-Hallinan M, Luchesi L, Pires ML, Tufik S. Sleep and sleepiness among Brazilian shift-working bus drivers. Chronobiol Int 2004; 21: 881-888. 